\title{
Stability of Quartic Functional Equation in Random 2- Normed Space
}

\author{
Roji Lather \\ Department of Mathematics, \\ Maharshi Dayanand Univeristy, Rohtak
}

\author{
Kusum Dhingra \\ Department of Mathematics, \\ Maharshi Dayanand University, Rohtak
}

\begin{abstract}
In this paper, we present the Hyers- Ulam- Rassias stability of quartic functional equation

$f(2 x+y)+f(2 x-y)=4 . f(x+y)+4 f(x-y)+24 f(x)-6 f(y)$ in Random 2- Normed space .
\end{abstract}

\section{Keywords}

Hyers-Ulam-Rassias stability, Quartic functional equation , Random 2- Normed space.

\section{INTRODUCTION}

In 1941, D.H. Hyers [2] has been studied the stability of function for a function from normed space to Banach space. He solved the problem given by Ulam [16] in 1940. He proved that for a function $\mathrm{f}: \mathrm{X} \rightarrow \mathrm{Y}$, a function between normed space $X$ and Banach space $Y$ satisfying

$\|\mathrm{f}(\mathrm{x}+\mathrm{y})-\mathrm{f}(\mathrm{x})-\mathrm{f}(\mathrm{y})\| \leq \delta$

for each $\mathrm{x}, \mathrm{y} \in \mathrm{X}$ and $\delta>0$. Then there exists a unique additive function $\mathrm{T}: \mathrm{X} \rightarrow \mathrm{Y}$ such that

$\|\mathrm{f}(\mathrm{x})-\mathrm{T}(\mathrm{x})\| \leq \delta$ for each $\mathrm{x} \in \mathrm{X}$.

Above result is generalized by Aoki [18] and Rassias [19] for additive mappings and linear mappings, respectively. A generalization of Rassias theorem was obtained by Gavruta [11] by replacing the unbounded Cauchy difference by a general control function in the spirit of Rassias approach.

In 1990, Rassias asked the question whether such a theorem can also be proved for $\quad p \geq 1$. In 1991, Gajda [25] gave an affirmative solution to this question for $p>1$. Gajda [25] as well Rassias and Semirl [20] investigated that one can not prove Rassias - type theorem when $\mathrm{p}=1$ ( $\mathrm{cf}$. the books of Czerwik [15], Hyers, Isac and Rassias [3]). In the similar way, using different methods, the stability problems for several functional equations have been extensively investigated by serval mathematicians([4-7], [12-14], [21-24] ).

The functional equation

$f(2 x+y)+f(2 x-y)=$

$$
4 . f(x+y)+4 f(x-y)+24 f(x)-6 f(y)
$$

is said to be quartic functional equation and every solution of quartic equation is said to quartic mapping. Karn Petapirak and Pasian Nakmahachalasint [9] proved the stability problem of quartic functional equation.

\section{PRELIMINARIES}

In this section, we recall some notations and basic definitions used in this article.

Definition 2.1 [1] : A distribution function is an element of $\Delta^{+}$, where $\Delta^{+}=\{\mathrm{f}: \mathrm{R} \rightarrow[0,1] ; \mathrm{f}$ is left-continuous, non decreasing, $f(0)=0$ and $f(+\infty)=1\}$ and the subset
$\mathrm{D}^{+} \subseteq \Delta^{+}$is the set

$\mathrm{D}^{+}=\left\{\mathrm{f} \in \Delta^{+} ; l^{-} \mathrm{f}((+\infty)=1\}\right.$.

Here $l \mathrm{f}(+\infty)$ denotes the left limit of the function $\mathrm{f}$ at the point $\mathrm{x}$. The space $\Delta^{+}$is partially ordered by the usual pointwise ordering of functions, i.e., $f \leq g$ if and only if $f(x) \leq g(x)$ for all $x \in R$. For any $a \in R, H_{a}$ is a distribution function defined by

$$
H_{a}(x)=\left\{\begin{array}{lll}
0 & \text { if } & x \leq a \\
1 & \text { if } & x>a
\end{array}\right.
$$

The set $\Delta$, as well as its subsets, can be partially ordered by the usual pointwise order : in this order, $\mathrm{H}_{0}$ is the maximal element in $\Delta^{+}$.

A triangle function is a binary operation on $\Delta^{+}$, namely a function $\mu: \Delta^{+} \times \Delta^{+} \rightarrow \Delta^{+}$that is associative, commutative, non decreasing and which has $\varepsilon_{0}$ as unit, that is, for all $\mathrm{f}, \mathrm{g}, \mathrm{h}$ $\in \Delta^{+}$, we obtain :

$$
\begin{array}{cl}
\text { i. } & \mu(\mu(\mathrm{f}, \mathrm{g}), \mathrm{h})=\mu(\mathrm{f}, \mu(\mathrm{g}, \mathrm{h})), \\
\text { ii. } & \mu(\mathrm{f}, \mathrm{g})=\mu(\mathrm{g}, \mathrm{f}), \\
\text { iii. } & \mu(\mathrm{f}, \mathrm{g})=\mu(\mathrm{g}, \mathrm{f}) \text { whenever } \mathrm{f} \leq \mathrm{g}, \\
\text { iv. } & \mu\left(\mathrm{f}, \mathrm{H}_{0}\right)=\mathrm{f} .
\end{array}
$$

A t-norm is a continuous mapping $*:[0,1] \times[0,1] \rightarrow[0,1]$ such that $([0,1], a)$ is abelian monoid with unit one and $\mathrm{c} * \mathrm{~d} \geq$ $a * b$ if $c \geq a$ and $d \geq b$ for all $a, b, c, d \in[0,1]$.

The concept of 2-normed space was first introduced in [17].

Definition 2.2[10] : Let $\mathrm{X}$ be a linear space dimension greater than 1 . Suppose $\|.,$.$\| is a real-valued function on X \times X$ satisfying the following conditions :

i. $\|\mathrm{x}, \mathrm{y}\|=0$ if and only if $\mathrm{x}, \mathrm{y}$ are linearly dependent vectors,

ii. $\|\mathrm{x}, \mathrm{y}\|=\|\mathrm{y}, \mathrm{x}\|$ for all $\mathrm{x}, \mathrm{y} \in \mathrm{X}$,

iii. $\|\lambda \mathrm{x}, \mathrm{y}\|=|\lambda|\|\mathrm{x}, \mathrm{y}\|$ for all $\lambda \in \mathrm{R}$ and for all $\mathrm{x}, \mathrm{y}$ $\in \mathrm{X}$,

iv. $\|\mathrm{x}+\mathrm{y}, \mathrm{z}\| \leq\|\mathrm{x}, \mathrm{z}\|+\|\mathrm{z}, \mathrm{y}\|$ for all $\mathrm{x}, \mathrm{y}, \mathrm{z} \in \mathrm{X}$

Then $\|.,$.$\| is called a 2-norm on X$ and the pair $(X,\|.,\|$. is called 2-normed linear space. Some of the basic properties of 2-norm are that they are non-negative and $\|x, y+\lambda x\|=\|$ $\mathrm{x}, \mathrm{y} \|$ for all $\lambda \in \mathrm{R}$ and all $\mathrm{x}, \mathrm{y} \in \mathrm{X}$.

Example 2.2[10] : Let $\mathrm{X}$ be a linear space with inner product $<.$, . $>$ and $\operatorname{dim}(X) \geq 2$. Then

$\|\mathrm{x}, \mathrm{y}\|=\left|\begin{array}{ll}<\mathrm{x}, \mathrm{x}> & <\mathrm{x}, \mathrm{y}> \\ <\mathrm{y}, \mathrm{x}> & <\mathrm{y}, \mathrm{y}\rangle\end{array}\right|^{\frac{1}{2}}$ is a 2-norm on $\mathrm{X}$. 
Gelet [8] and Mursaleen introduced the notion of random 2normed space (or in short RTN space)

Definition2.3[1] : Let $X$ be a linear space of dimension greater than one, $\mu$ is a triangle function, and $\mathrm{F}: \mathrm{X} \times \mathrm{X} \rightarrow \Delta^{+}$. Then $F$ is called a probabilistic 2-norm on $X$ and $(X, F, \mu)$ a probabilistic 2-normed space if the following conditions are fulfilled :

(i) $F_{x, y}(t)=H_{0}(t)$ if $x$ and $y$ are linearly dependent, where $F_{x, y}(t)$ denotes the value of $F_{x, y}$ at $t \in R$,

(ii) $\mathrm{F}_{\mathrm{x}, \mathrm{y}} \neq \mathrm{H}_{0}$ if $\mathrm{x}$ and $\mathrm{y}$ are linearly independent,

(iii) $F_{x, y}=F_{y, x}$ for every $x, y$ in $X$,

(iv) $\mathrm{F}_{\alpha \mathrm{x}, \mathrm{y}}(\mathrm{t})=\mathrm{F}_{\mathrm{x}, \mathrm{y}}\left(\frac{\mathrm{t}}{|\alpha|}\right)$ for every $\mathrm{t}>0, \alpha \neq 0$ and $\mathrm{x}, \mathrm{y} \in \mathrm{X}$,

(v) $\mathrm{F}_{\mathrm{x}+\mathrm{y}, \mathrm{z}} \geq \mu\left(\mathrm{F}_{\mathrm{x}, \mathrm{z}}, \mathrm{F}_{\mathrm{y}, \mathrm{z}}\right)$ whenever $\mathrm{x}, \mathrm{y}, \mathrm{z} \in \mathrm{X}$. If (v) is replaced by

(v') $\mathrm{F}_{\mathrm{x}+\mathrm{y}, \mathrm{z}}\left(\mathrm{t}_{1}+\mathrm{t}_{2}\right) \geq \mathrm{F}_{\mathrm{x}, \mathrm{z}}\left(\mathrm{t}_{1} * \mathrm{~F}_{\mathrm{y}, \mathrm{z}}\left(\mathrm{t}_{2}\right)\right.$ for all $\mathrm{x}, \mathrm{y}, \mathrm{z} \in \mathrm{X}$ and $\mathrm{t}_{1}$, $\mathrm{t}_{2} \in \mathrm{R}_{0}^{+}$, then triple $\quad(\mathrm{X}, \mathrm{F}, *)$ is called a random 2normed space.

Example 2.3[1] : Let $(X,\|.,\|$.$) be a 2-normed space with \|$ $\mathrm{x}, \mathrm{z}\|=\| \mathrm{x}_{1} \mathrm{z}_{2}-\mathrm{x}_{2} \mathrm{z}_{1} \|, \mathrm{x}=\left(\mathrm{x}_{1}, \mathrm{x}_{2}\right), \quad \mathrm{z}=\left(\mathrm{z}_{1}, \mathrm{z}_{2}\right)$ and $\mathrm{a} * \mathrm{~b}=$ $\mathrm{ab}$ for $\mathrm{a}, \mathrm{b} \in[0,1]$. For all $\mathrm{x} \in \mathrm{X}, \mathrm{t}>0$ and non zero $\mathrm{z} \in \mathrm{X}$, Consider

$F_{x, z}(t)=\left\{\begin{array}{lll}\frac{t}{t+\|x, z\|} & \text { if } t>0 \\ 0 & \text { if } t \leq 0\end{array}\right.$

Then $(\mathrm{X}, \mathrm{F}, *)$ is a random 2-normed space.

Remark 2.3 : Every 2-normed space $(X,\|.,\|$.$) can be made$ a random 2-normed space in natural way, by setting $\mathrm{F}_{\mathrm{x}, \mathrm{y}}(\mathrm{t})=$ $\mathrm{H}_{0}(\mathrm{t}-\|\mathrm{x}, \mathrm{y}\|)$, for every $\mathrm{x}, \mathrm{y} \in \mathrm{X}, \mathrm{t}>0$

and $\mathrm{a} * \mathrm{~b}=\min \{\mathrm{a}, \mathrm{b}\}, \mathrm{a}, \mathrm{b} \in[0,1]$.

Definition 2.4[1] : A sequence $x=\left(x_{k}\right)$ is convergent in $(X, F$, *) or simply F-convergent to $l$ if for every $\epsilon>0$ and $\theta \in(0,1)$ there exists $\mathrm{k}_{0} \in \mathrm{N}$ such that $\mathrm{F}_{\mathrm{x}_{\mathrm{k}}-l, \mathrm{z}}(\varepsilon)>1-\theta$ whenever $\mathrm{k} \geq \mathrm{k}_{0}$ and non zero $\mathrm{z} \in \mathrm{X}$. In this case, we write $\mathrm{F}-\lim _{\mathrm{k} \rightarrow \infty} \mathrm{x}_{\mathrm{k}}=l$ and $l$ is called the F-limit of $x=\left(x_{k}\right)$.

Definition 2.5[1] : A sequence $x=\left(x_{k}\right)$ is said to be Cauchy sequence in $(X, F, *)$ for every $\epsilon>0, \theta>0$ and non-zero $z \in$ $X$ there exist a number $\mathrm{N}=\mathrm{N}(\epsilon, \mathrm{z})$ such that $\operatorname{limF}_{\mathrm{x}_{\mathrm{n}}-\mathrm{x}_{\mathrm{m}}, \mathrm{z}}(\varepsilon)>1-\theta$ for all $\mathrm{n}, \mathrm{m} \geq \mathrm{N}$. RTN-space $(\mathrm{X}, \mathrm{F}, *)$ is said to be complete if every F-Cauchy is F-convergent. In this case, $\left(\mathrm{X}, \mathrm{F},{ }^{*}\right)$ is called random 2-Banach space.

\section{MAIN RESULT}

In this section, we shall suppose that $\mathrm{X}$ and $\mathrm{Y}$ are linear spaces; $\left(\mathrm{X}, \mathrm{F},{ }^{*}\right)$ and $\left(\mathrm{Z}, \mathrm{F}^{\prime},{ }^{*}\right)$ are random 2-normed spaces; and $(\mathrm{Y}, \mathrm{F}, *)$ is a random 2-Banach space. Let $\phi$ be a function from $\mathrm{X} \times \mathrm{X}$ to $\mathrm{Z}$. A mapping $\mathrm{f}: \mathrm{X} \rightarrow \mathrm{Y}$ is said to be $\phi$-approximately quartic mapping if

$\mathrm{F}_{\mathrm{E}_{\mathrm{x}, \mathrm{y}}, \mathrm{z}}(\mathrm{t}) \geq \mathrm{F}_{\varphi(\mathrm{x}, \mathrm{y}), \mathrm{z}}^{\prime}(\mathrm{t})$

Theorem 3.1 : Let us assume that a function $\phi$ : $X \times X \rightarrow Z$ satisfies $\phi(2 x, 2 y)=\alpha \phi(x, y)$ for all $x, y \in X$ and $\alpha \neq 0$. Let $\mathrm{f}: \mathrm{X} \rightarrow \mathrm{Y}$ be a function. For some

$\phi$-approximately quartic $0<\alpha<16$

$\mathrm{F}_{\psi(2 \mathrm{x}, 2 \mathrm{y}), \mathrm{z}}^{\prime}(\mathrm{t}) \geq \mathrm{F}_{\alpha \psi(\mathrm{x}, \mathrm{y}), \mathrm{z}}^{\prime}(\mathrm{t})$

and $\quad \lim _{n \rightarrow \infty} F_{\psi\left(2^{n} x, 2^{n} y\right), z}^{\prime}\left(16^{n} t\right)=1$

for all $\mathrm{x}, \mathrm{y} \in \mathrm{X}, \mathrm{t}>0$ and non-zero $\mathrm{z} \in \mathrm{X}$. Then there exists a unique quartic mapping $\mathrm{C}: \mathrm{X} \rightarrow \mathrm{Y}$ such that

$\mathrm{F}_{\mathrm{C}(\mathrm{x})-\mathrm{f}(\mathrm{x}), \mathrm{z}}(\mathrm{t}) \geq \mathrm{F}_{\psi(\mathrm{x}, 0), \mathrm{z}}^{\prime}((16-\alpha) \mathrm{t})$

for all $\mathrm{x} \in \mathrm{X}, \mathrm{t}>0$ and non-zero $\mathrm{z} \in \mathrm{X}$.

Proof : Taking $y=0$ in equation (3.1). Then for all $x \in X, t>$ 0 and non-zero $\mathrm{z} \in \mathrm{X}$

$\mathrm{F}_{\frac{f(2 x)}{16}-f(x), z}\left(\frac{t}{32}\right) \geq F_{\psi(x, 0)}^{\prime}(t)$

Replacing $\mathrm{x}$ by $2^{\mathrm{n}} \mathrm{x}$ in (3.4) and applying (3.2), we have

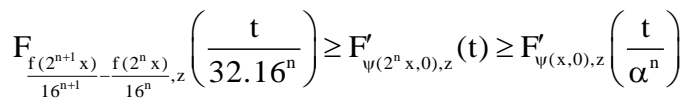

for all $\mathrm{x} \in \mathrm{X}, \mathrm{t}>0$ and non-zero $\mathrm{z} \in \mathrm{X}$; and for all $\mathrm{n} \geq 0$. By replacing $t$ by $\alpha^{\mathrm{n}} \mathrm{t}$, we obtain $\mathrm{F}_{\frac{\mathrm{f}\left(\mathrm{2}^{\mathrm{n}+1} x\right)}{16^{\mathrm{n}+1}}-\frac{\mathrm{f}\left(2^{\mathrm{n}} \mathrm{x}\right)}{16^{\mathrm{n}}}, \mathrm{z}}\left(\frac{\alpha^{\mathrm{n}} \cdot \mathrm{t}}{32 \cdot 16^{\mathrm{n}}}\right) \geq \mathrm{F}_{\psi(\mathrm{x}, 0), \mathrm{z}}^{\prime}(\mathrm{t})$

It follows from $\frac{\mathrm{f}\left(2^{\mathrm{n}} \mathrm{x}\right)}{16^{\mathrm{n}}}-\mathrm{f}(\mathrm{x})=\sum_{\mathrm{k}=0}^{\mathrm{n}=1}\left(\frac{\mathrm{f}\left(2^{\mathrm{k}+1} \mathrm{x}\right.}{16^{\mathrm{k}+1}}-\frac{\mathrm{f}\left(2^{\mathrm{k}} \mathrm{x}\right)}{16^{\mathrm{k}}}\right)$ and (3.5) that

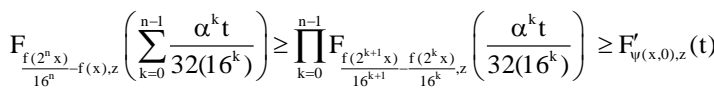

(3.6)

for all $\mathrm{x} \in \mathrm{X}, \mathrm{t}>0$ and $\mathrm{n}>0$ where $\prod_{\mathrm{j}=1}^{\mathrm{n}} \mathrm{a}_{\mathrm{j}}=\mathrm{a}_{1} * \mathrm{a}_{2} * \ldots . \mathrm{a}_{\mathrm{n}}$

By replacing $\mathrm{x}$ with $2^{\mathrm{m}} \mathrm{x}$, we obtain

$$
\begin{aligned}
& \mathrm{F}_{\frac{\mathrm{f}\left(2^{\mathrm{n}+\mathrm{m} x)}\right.}{16^{\mathrm{n}+\mathrm{m}}}-\frac{\mathrm{f}\left(2^{\mathrm{m} x)},\right.}{16^{\mathrm{m}}}, \mathrm{z}}\left(\sum_{\mathrm{k}=0}^{\mathrm{n}-1} \frac{\alpha^{\mathrm{k}} \mathrm{t}}{32(16)^{\mathrm{k}+\mathrm{m}}}\right) \geq \mathrm{F}_{\psi\left(2^{\mathrm{m} x, 0), z}\right.}^{\prime}(t) \geq \mathrm{F}_{\psi(\mathrm{x}, 0), \mathrm{z}}^{\prime}\left(\frac{\mathrm{t}}{\alpha^{\mathrm{m}}}\right) \text { Then } \\
& \mathrm{F}_{\frac{\mathrm{f}\left(2^{\mathrm{n}+\mathrm{m}} x\right)}{16^{n+m}}-\frac{f\left(2^{\mathrm{m}} \mathrm{x}\right)}{16^{m}}, z}\left(\sum_{\mathrm{k}=\mathrm{m}}^{\mathrm{n}+\mathrm{m}-1} \frac{\alpha^{\mathrm{k}} \mathrm{t}}{32(16)^{\mathrm{k}}}\right) \geq \mathrm{F}_{\psi(\mathrm{x}, 0), \mathrm{z}}^{\prime}(\mathrm{t})
\end{aligned}
$$

for all $\mathrm{x} \in \mathrm{X}, \mathrm{t}>0, \mathrm{~m}>0, \mathrm{n} \geq 0$ and non-zero $\quad \mathrm{z} \in X$. Hence

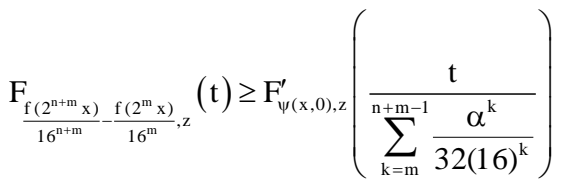

for all $\mathrm{x} \in \mathrm{X}, \mathrm{t}>0, \mathrm{~m}>0, \mathrm{n} \geq 0$ and non-zero $\mathrm{z} \in \mathrm{X}$. Since $0<\alpha<16$ and $\sum_{\mathrm{k}=0}^{\infty}\left(\frac{\alpha}{16}\right)^{\mathrm{k}}<\infty$, the Cauchy criterion for convergence proves that $\left(\frac{\mathrm{f}\left(2^{\mathrm{n}} \mathrm{x}\right)}{16^{\mathrm{n}}}\right)$ is a Cauchy sequence in $(\mathrm{Y}, \mathrm{F}, *)$. Since $(\mathrm{Y}, \mathrm{F}, *)$ is complete, this sequence converges 
to some point $\mathrm{C}(\mathrm{x}) \in \mathrm{Y}$. Fix $\mathrm{x} \in \mathrm{X}$ and put $\mathrm{m}=0$ in (3.7) to obtain

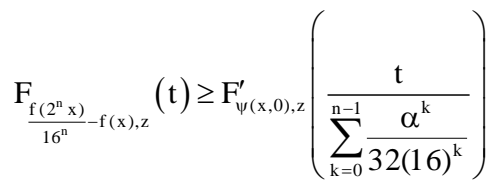

for all $\mathrm{t}>0, \mathrm{n}>0$ and non-zero $\mathrm{z} \in \mathrm{X}$. Thus we get

$$
\begin{array}{r}
F_{C(x)-f(x), z}(t) \geq F_{C(x)-\frac{f\left(2^{n} x\right)}{16^{n}}, z}\left(\frac{t}{2}\right) * F_{\frac{f\left(2^{n} x\right)}{16^{n}}-f(x), z}\left(\frac{t}{2}\right) \\
\geq F_{\psi(x, 0), z}^{\prime}\left(\frac{t}{\left.\sum_{k=0}^{n-1} \frac{\alpha^{k}}{16.16^{k}}\right)}\right.
\end{array}
$$

for large $n$. Taking the limit as $\mathrm{n} \rightarrow \infty$ and applying the definition of Random 2-Normed Space, we get

$\mathrm{F}_{\mathrm{C}(\mathrm{x})-\mathrm{f}(\mathrm{x}), \mathrm{z}}(\mathrm{t}) \geq \mathrm{F}_{\psi(\mathrm{x}, 0), \mathrm{z}}^{\prime}((16-\alpha) \mathrm{t})$

Change $\mathrm{x}$ and $\mathrm{y}$ by $2^{\mathrm{n}} \mathrm{x}$ and $2^{\mathrm{n}} \mathrm{y}$, respectively, in (3.1), we obtain

$\frac{\mathrm{F}_{\mathrm{E} 2^{\mathrm{n}} x, 2^{\mathrm{n}} \mathrm{y}}}{16^{\mathrm{n}}, z}(\mathrm{t}) \geq \mathrm{F}_{\psi\left(2^{\mathrm{n} x}, 2^{\mathrm{n} y}\right), z}^{\prime}\left(16^{\mathrm{n}} \mathrm{t}\right)$

for all $\mathrm{x}, \mathrm{y} \in \mathrm{X}, \mathrm{t}>0$ and non-zero $\mathrm{z} \in \mathrm{X}$.

Since $\quad \lim _{n \rightarrow \infty} F_{\psi\left(2^{n} \times, 2^{n} y\right), z}^{\prime}\left(16^{n} t\right)=1$,

We conclude that $\mathrm{C}$ satisfy (1.1). To prove the uniqueness of the quartic function $\mathrm{C}$, let us suppose that there exist a quartic function $\mathrm{Q}: \mathrm{X} \rightarrow \mathrm{Y}$ which satisfy (3.3). For fix $\mathrm{x} \in \mathrm{X}$, clearly $\mathrm{C}\left(2^{\mathrm{n}} \mathrm{x}\right)=16^{\mathrm{n}} \mathrm{C}(\mathrm{x})$ and

$\mathrm{Q}\left(2^{\mathrm{n}} \mathrm{x}\right)=16^{\mathrm{n}} \mathrm{Q}(\mathrm{x}) \quad$ for all $\mathrm{n} \in \mathrm{N}$.

It follows from (3.3) that

$$
\begin{aligned}
& \mathrm{F}_{\mathrm{C}(\mathrm{x})-\mathrm{Q}(\mathrm{x}), \mathrm{z}}(\mathrm{t})=\mathrm{F}_{\frac{\mathrm{C(2^{ \textrm {n } } \mathrm { x } )}}{16^{\mathrm{n}}}-\frac{\mathrm{Q}\left(2^{\mathrm{n}} \mathrm{x}\right)}{16^{\mathrm{n}}}, \mathrm{z}}(\mathrm{t}) \\
& \geq \mathrm{F}_{\frac{\mathrm{C}\left(2^{\mathrm{n}} \mathrm{x}\right)}{16^{\mathrm{n}}}-\frac{\mathrm{f}\left(2^{\mathrm{n} x} \mathrm{x}\right)}{16^{\mathrm{n}}}, \mathrm{z}}\left(\frac{\mathrm{t}}{2}\right) * \mathrm{~F}_{\frac{\mathrm{f}\left(2^{\mathrm{n}} \mathrm{x}\right)}{16^{\mathrm{n}}}-\frac{\mathrm{Q}\left(2^{\mathrm{n}} \mathrm{x}\right)}{16^{\mathrm{n}}}, \mathrm{z}}\left(\frac{\mathrm{t}}{2}\right) \\
& \geq \mathrm{F}_{\psi\left(2^{\mathrm{n}} \times 0\right), \mathrm{z}}^{\prime}\left(\frac{16^{\mathrm{n}}(16-\alpha) \mathrm{t}}{2}\right) \\
& \geq \mathrm{F}_{\psi(\mathrm{x}, 0), \mathrm{z}}^{\prime}\left(\frac{16^{\mathrm{n}}(16-\alpha) \mathrm{t}}{2 \alpha^{\mathrm{n}}}\right) \\
& \text { So, } \quad F_{\psi(x, 0), z}^{\prime}\left(\frac{16^{n}(16-\alpha) t}{2 \alpha^{n}}\right)=1
\end{aligned}
$$

Thus, $\mathrm{F}_{\mathrm{C}(\mathrm{x})-\mathrm{Q}(\mathrm{x}), \mathrm{z}}(\mathrm{t})=1$ for all $\mathrm{x} \in \mathrm{X}, \mathrm{t}>0$ and non-zero $\mathrm{z} \in$ $X$. Hence $\mathrm{C}(\mathrm{x})=\mathrm{Q}(\mathrm{x})$.

\section{REFERENCES}

[1] A. Alotaibi, S.A. Mohiuddine; On the stability of a cubic functional equation in random 2-normed spaces, Advances in Difference Equations, 1,39 (2012) pp. 1-10.

[2] D.H. Hyers; On the stability of the linear functional equation, Proc. Nat. Acad. Sci. U.S.A., 27 (1941) 222224.

[3] D.H. Hyers, G. Isac and Th. M. Rassias; Stability of functional equations in several variables, Birkhauser, Basel, (1998).

[4] E. Elqorachi; Y. Manar and Th. M. Rassias; Hyers-Ulam stability of the quadratic functional equation, Int. J. Non linear Anal. Appl. 1(2010) 11-20.

[5] E. Elqorachi, Y. Manar and Th. M. Rassias; Hyers-Ulam stability of quadratic and Jensen functional equations on unbounded domains, J. Math. Sci. Advances and Applications 4(2010) 287-301.

[6] G.L. Forti; An existence and stability theorem for a class of functional equations, Stochastica 4(1980) 23-30.

[7] G.L. Forti; Hyers-Ulam stability of functional equations in several variables, Aequationes Math. 50(1995) 143190.

[8] I. Golet; On probabilistic 2-normed spaces, Novi Sad J. Math. 35, (2006) 95-102.

[9] K. Petapirak and P. Nakmahachalasint; A quartic functional equation and its generalized Hyers-UlamRassias stability, Thai. J. of Maths. Spec, Issue (Annual Meeting in Math.) (2008) 77-84.

[10] M .Kumar, Anil; Stability of Cubic Functional Equations in 2- Normed Space, 2, 3 (2015) 55-58.

[11] P. Gavruta; A generalization of the Hyers-Ulam-Rassias stability of approximately additive mappings, J. Math. Anal. Appl. 184(1994) 431-436.

[12] S.M. Jung; Hyers-Ulam-Rassias stability of functional equations in nonlinear analysis, springer, New York, (2011).

[13] S.M. Jung; Stability of the quadratic equation of Pexider type, Abh. Math. Sem Univ. Hamburg 70(2000) 175 190.

[14] S.M. Jung and B. Kim; Local stability of the additive functional equation and its applications, IJMMS (2003) 15-26.

[15] S. Czerwik; On the stability of the quadratic mapping in normed spaces, abh. Math. Sem. Univ. Hamburg. 62 (1992) 59-64.

[16] S.M. Ulam; A collection of Mathematical Problems, Interscience Publ. New York, 1961. Problems in Modern Mathematics, Wiley, New York, 1964.

[17] S. Gahler; Linear 2-normierte R aumen, Math. Nachr, (28) (1964)1-43.

[18] T. Aoki; On the stability of the linear transformation $n$ Banach Spaces, J. Math. Soc. Japan 2 (1950) 64-66.

[19] Th. M. Rassias; On the stability of linear mapping in Banach spaces, Proc. Amer. Math. Soc. 72 (1978) 297 300 . 
[20] Th. M. Rassias and P. Semrl; On the behaviour of mappings which do not satisfy Hyers-Ulam stability, Proc. Amer. Math. Soc. 114(1992) 989-993.

[21] Th. M. Rassias; On a modified Hyers-Ulam sequence, J. Math. Anal. Appl. 158 (1991) 106-113.

[22] Th. M. Rassias; The problem of S.M. Ulam for approximately multiplicative mapping, J. Math. Anal. Appl. 246 (2000) 352-378.
[23] Th. M. Rassias; On the stability of the functional equations and a problem of Ulam, Acta Appl. Math. 62 (2000) 23-130.

[24] Th. M. Rassias; On the stability of functional equations in Banach spaces, J. Math. Anal. Appl. 251(2000) 264284.

[25] Z. Gajda; On stability of additive mappings, Internat. J. Math. Math. Sci. 14(1991) 431-434. 